\title{
Prevalence and Risk Factors Associated with Campylobacter Infection in Diarrheal Patients in Busia County, Kenya
}

\author{
Tom T. Ouko ${ }^{*}\left(\mathbb{D}\right.$, Andrew K. Nyerere ${ }^{2}$, John M. Njeru ${ }^{1}$, Eric M. Fèvre ${ }^{3,4}$, Samuel Kariuki ${ }^{1}$ \\ ${ }^{1}$ Centre for Microbiology Research, Kenya Medical Research Institute, Nairobi, Kenya \\ ${ }^{2}$ Department of Medical Microbiology, Jomo Kenyatta University of Agriculture and Technology, Nairobi, Kenya \\ ${ }^{3}$ Institute of Infection, Veterinary and Ecological Sciences, University of Liverpool, Liverpool, United Kingdom \\ ${ }^{4}$ International Livestock Research Institute, Nairobi, Kenya \\ Email: `tomoukot2@gmail.com, knyerere@jkuat.ac.ke, jnjeru@kemri.org, eric.fevre@liverpool.ac.uk, skariuki@kemri.org, \\ samkariuki2@gmail.com
}

How to cite this paper: Ouko, T.T., Nyerere, A.K., Njeru, J.M., Fèvre, E.M. and Kariuki, S. (2021) Prevalence and Risk Factors Associated with Campylobacter Infection in Diarrheal Patients in Busia County, Kenya. Advances in Microbiology, 11, 657680.

https://doi.org/10.4236/aim.2021.1111048

Received: September 27, 2021

Accepted: November 23, 2021

Published: November 26, 2021

Copyright $\odot 2021$ by author(s) and Scientific Research Publishing Inc. This work is licensed under the Creative Commons Attribution International License (CC BY 4.0).

http://creativecommons.org/licenses/by/4.0/

(c) (i) Open Access

\begin{abstract}
Introduction: Campylobacter are zoonotic bacteria that cause gastroenteritis worldwide with the species, Campylobacter jejuni and Campylobacter coli commonly associated with human diarrhea. Transmission is mainly through direct contact with farm animals, consumption of chicken and contaminated water. There is paucity of data on the epidemiology of Campylobacter in developing countries despite its global widespread and expansion of poultry farming; hence there is the need to explore and build on the available data. This study aimed at determining prevalence and homestead risk practices associated with Campylobacter infection in diarrheal patients in Busia County. Methods: A cross-sectional study was conducted from February, 2017 to April, 2019. Stool samples were collected from patients of all ages attending Busia County referral Hospital and structured questionnaires on homestead associated risk practices administered. Isolation and identification of Campylobacter species was performed using standard culture method on Modified Charcoal Cefoperazone Deoxycholate medium and confirmed by mPCR. Factors associated with Campylobacter infection were evaluated using logistic regression analysis. Results: A total of 132 (11.6\%) Campylobacter comprising $89.2 \%$ C. jejuni and $10.8 \%$ C. coli were isolated from 1200 diarrhoegenic patients sampled. Isolation rate was higher in children aged $<2$ years $(13.7 \%)$ as compared to $2-5$ years $(10.2 \%)$ and $>5$ years $(9.4 \%)$. Multilevel logistic models showed that homestead poultry farming was a significant risk associated with Campylobacter infection in $<2$ years [odds ratio (OR) 9.02; 95\%
\end{abstract}


CI: 3.19 - 25.47, P < 0.001], 2 - 5 years (OR 6.47, 95\% CI: $2.71-15.45, \mathrm{P}<$ 0.001 ) and $>5$ years (OR 10.05; 95\% CI: $2.60-24.29, \mathrm{P}<0.001$ ). Other homestead risk practices linked to children $<2$ years were drinking of pond water (OR 7.43, 95\% CI: 1.70 - 16.33, P < 0.001), repeated use of same food cutting board without soap wash by food handlers during food preparation (OR 3.32, 95\% CI: $1.28-8.62, \mathrm{P}=0.014$ ) and female gender (OR 6.68, 95\% CI: $2.51-17.75, \mathrm{P}<0.001$ ). However, use of toilet (OR 0.08, 95\% CI: $0.02-0.27$, $\mathrm{P}<0.001$ ) and breast feeding practices (OR 0.24, 95\% CI: $0.11-0.52, \mathrm{P}<$ $0.001)$ were protective. Patients aged 2 - 5 years who had contact with domestic pets (OR 5.72, 95\% CI: $1.21-10.04, \mathrm{P}=0.016$ ), fed on chicken meat (OR 2.83, 95\% CI: $1.32-6.04, \mathrm{P}=0.007$ ), drunk untreated pond water (OR 6.51, 95\% CI: 1.57 - 13.59, P = 0.001) and female gender (OR 8.25, 95\% CI: 3.43 19.81, $\mathrm{P}<0.001)$ were at risk of Campylobacter infection while those who lived in urban areas (OR 0.47, 95\% CI: $0.20-0.82, \mathrm{P}=0.041$ ) were protected. Contact with infected diarrheal person from the same household (OR 4.72, 95\% CI: $2.10-10.52, \mathrm{P}=0.006)$ and consumption of raw milk (OR 7.14, 95\% $\mathrm{CI}: 1.96-18.24, \mathrm{P}=0.001)$ posed risk among those aged $>5$ years respectively. Conclusion: Campylobacter jejuni is the leading cause of Campylobacter infections in diarrheal patients. Personal hygiene awareness of mothers/caregivers and proper animal husbandry especially where livestock-human interaction is common are important practices which require the County government support. Further studies are required on sex specific age difference, other social economic factors, domestic animals and the role played by the environment in the transmission of Campylobacter infection. These would advance knowledge and understanding on source attribution and transmission dynamics for effective control and management of the infection.

\section{Keywords}

Risk Factors, Prevalence, Diarrhea, Campylobacter

\section{Introduction}

The genus Campylobacter is a zoonotic foodborne pathogen that causes diarrheal disease; the two major species are Campylobacter jejuni and Campylobacter coli [1]. Campylobacter jejuni is responsible for over $90 \%$ of human campylobacteriosis and is frequently isolated from poultry (81\%) while $C$. coli causes less than $10 \%$ of human disease and is most frequently isolated from pigs (100\%) [2] [3].

Campylobacteriosis is a problem and an economic burden to human population worldwide with an estimated 96 million cases annually, exceeding those of salmonellosis, shigellosis and E. coli: $0157 \mathrm{H} 7$ combined [4]. It is the third most common cause of hospitalization globally after Rotavirus and Salmonella infections and is associated with the loss of up to 7.5 million disability-adjusted life 
years [5] [6]. Human Campylobacter infections are categorized into gastrointestinal conditions, including inflammatory bowel diseases (IBD), diarrhea, Barrett's esophagus and colorectal cancer [7] and extragastrointestinal manifestations including bacteremia, lung infections, brain abscesses, meningitis, and reactive arthritis [8]. Incubation period is 1 - 10 days and clinical symptoms range from acute abdominal pain, watery diarrhoea, fever, nausea, vomiting, headache and muscle pain [9] which may persist for a week or longer [10]. The severity of illness varies from mild malaise to dehydration sufficient to warrant hospitalization and can be life-threatening [11].

Although campylobacteriosis is largely perceived as a foodborne infection with consumption and handling of poultry and poultry-related products being the major source of all Campylobacter infections [12], there is increasing evidence of additional routs of transmission including direct contact with other farm animals, consumption of undercooked foods and contaminated environment [13] [14]. Wild birds also play a role as reservoirs and can spread Campylobacter to humans through the environment [15]. Human-to-human transmission has been observed, although at low frequencies [16].

The epidemiology of Campylobacter enteritis differs between high- and low-income countries [17]. In high-income countries, clinical signs are symptomatic and occur in all age groups [18] whereas in low resource settings, most cases are asymptomatic with young children being more predisposed due to underdeveloped immunity. Adults acquire a level of protective immunity following repeated exposure and become predisposed when immunity gets low at senior age. Globally, the distribution of Campylobacter is attributed to asymptomatic colonization of the intestinal tract in a wide range of livestock species, use of animals manure, drinking contaminated water and poor hygiene conditions [19] [20] [21]. Studies have suggested that the incidence of Campylobacter enteritis is on the rise globally [22]. This increase has been noted much more in developed countries due to improved awareness and advances in detection practices [23].

In low and middle income countries (LMICs) such as Kenya, sources of Campylobacter infections have been less well documented due to lack of awareness and advances in detection practices to undertake national surveillance programmes and build a National epidemiological data banks of the disease. However, the available data indicate that the infection is endemic and on the rise [23]. The limited reports on Campylobacter are estimates from laboratory-based surveillance studies of pathogens responsible for diarrhoea [24] [25]. In Tanzania, the prevalence of human Campylobacter enteritis was reported at $21.6 \%$ [26] and between $12 \%-12.6 \%$ in Kenya [27]. Because of the importance of this disease and the rise in poultry farming in Kenya, this study was carried out with an aim of determining the prevalence and homestead risk practices associated with Campylobacter infection in diarrheal patients in Busia County, a region marked by high prevalence of HIV and proliferation of small-holder livestock production with over $95 \%$ of households keeping poultry [28]. 


\section{Materials and Methods}

\subsection{Study Design and Settings}

This was a cross-sectional study conducted between February 2017 and April, 2019 in Busia County referral Hospital that provides health care services to the population of Busia County in Western Kenya. Busia County has an area 1696 $\mathrm{km}^{2}$ and borders Uganda to the north, north-east and west, Lake Victoria to the south west, Siaya to the south and south-east and Kakamega and Bungoma to the east. The County has a population of 893,681 people ( $47 \%$ male and $53 \%$ female), according to the 2019 National Census. Agriculture is the mainstay for the economy and contributes approximately $50 \%$ of the household incomes [29]. The region has the highest rural human and livestock population densities and interaction of human and livestock in East Africa, operating in a mixed smallholder livestock production system [28]. Most households keep livestock, with the most common species being indigenous chickens. In addition to high rates of household livestock ownership, the community commonly slaughter and prepare chicken meals at home and rarely buy chicken from the few available retail outlets consequently leading to high exposures and transmission of zoonotic diseases [28] with regards to urban population, only Busia and Malaba towns in the County meet the minimum population threshold of 10,000 people for an urban center as per the section 8 and 9 of the Urban Areas and Cities Act 2011.

\subsection{Study Population}

The study population consisted of all patients presenting with diarrhea who sought treatment at the outpatient department at Busia County Hospital from February 2017 to April 2019.

\subsection{Recruitment Strategy}

After obtaining consent/assent from the adult participants and guardian/child, a systematic recruitment of the diarrhoeal (defined as passing of loose stool at least 3 times a day) patients [30] was conducted by requesting for stool sample in a clean plastic poly pot or rectal swab from children who could not pass stool. Semi-structured questionnaire was administered to obtain data on exposures in the 10 days before the onset of symptoms. The questionnaire comprised several sections, each representing different exposure groups and was pre-tested before the main recruitment for consistency. The interview was conducted in Kiswahili, English or Luhya depending on the language that was best understood by the respondent. Parent/guardians of the participating children were asked to complete the questionnaire on behalf of children.

The exposure variables were chosen on the basis of biological plausibility and previous knowledge on the risks associated with Campylobacter infection in other settings [13] [20] [21], and included socio-demographic factors such as age, residence, educational level and occupation. The occupation was divided 
into business which referred to those who earned livelihood by engagement in income generating activities such as working in hotels, local markets, shops and public transportation; the employed which referred to those who were salaried and worked in government, companies or NGOs; the unemployed which referred to those without any work with consistent income and finally those involved in poultry farming as their main upkeep; Behavioral and socio-economic factors included regular usage of toilet facilities within the homestead, types of foods commonly eaten and where purchased, exposure to infected diarrheal person(s) within the same household, pets and local and or international travel, types of houses lived in, source of cooking and lighting energy. The clinical section comprised of symptoms of Campylobacter enteritis and status on expanded immunization program (EIP) vaccine, any long term medication and immunosuppressive treatment based on a 4-week history.

\subsection{Inclusion Criteria}

Diarrheal patients of all ages seeking treatment at the outpatient department, Busia County Hospital who consented/assented to participate in the study and who self-reported to have not been on antibiotics for the previous 5 days.

\subsection{Exclusion Criteria}

Non-diarrhoeal cases and those that declined to participate.

\subsection{Specimen Collection and Isolation of Campylobacter Species}

Fresh stool/rectal swab samples were collected into a clean plastic poly-pot from diarrheal patients and transported in Amies media within 2 hours in cool box to the Centre for Infectious and Parasitic Diseases Control Research (CIPDCR), KEMRI, Busia laboratory for Campylobacter isolation. Standard microbiological techniques were used to culture and isolate Campylobacter jejuni and Campylobacter coli as described before [31]. Briefly; a gram of faecal sample or rectal swab was cultured on Exeter enrichment broth containing nutrient broth supplemented with lysed horse blood and incubated at $42^{\circ} \mathrm{C}$ aerobically for 24 hours. A sub-culture was done by passing $100 \mu \mathrm{l}$ of the enrichment broth culture on $0.45 \mu \mathrm{m}$ cellulose nitrate filter onto modified Cefoperazone Charcoal Deoxycholate Agar (mCCDA) supplemented with SR155 (Oxoid) and incubated at $42^{\circ} \mathrm{C} \pm 1^{\circ} \mathrm{C}$ for $48 \pm 4 \mathrm{~h}$ under microaerobic conditions $\left(5 \% \mathrm{O}_{2}, 10 \% \mathrm{CO}_{2}\right.$, and $85 \% \mathrm{~N}_{2}$ ) generated by CampyGen ${ }^{\mathrm{TM}}$ (Oxoid CN0035). Identification of Campylobacter was by characteristic appearance on the culture medium (moist, creamy-grey and flat-spreading), gram stain, oxidase test, catalase reaction hydrolysis of hippurate and indoxyl acetate and confirmed by multiplex PCR ( $m$ PCR). The reference standard strain $C$. jejuni (LMG 13646) was used for quality control [32].

\subsection{Molecular Identification of Campylobacter}

Multiplex PCR ( $m$ PCR) was used for confirmation of the suspected Campylo- 
bacter isolates by using genus and species specific primers as described by Bang et al., and Linton et al., [33] [34]. For genus identification of Campylobacter, 16S rRNA region was amplified using $C 412 F$ and $C 1228 R$ primers. Species-specific identification of $C$. jejuni and $C$. coli was done by targeting the hipO gene which codes for hippuricase enzyme with a $344 \mathrm{bp}$, and the asp $\mathrm{K}$ gene coding for aspartokinase with a $500 \mathrm{bp}$, respectively (Table 1). The PCR products were separated and identified by gel electrophoresis using $1.8 \%$ agarose containing 0.1 $\mu \mathrm{g} / \mathrm{ml}$ ethidium bromide.

\subsection{Data Management and Analysis}

The data were entered and analyzed using SPSS (IBM Corp., Armonk, NY, USA) version 21. Binary logistic regression was used to model predictors of Campylobacter infection adjusting for factors identified to be significant at $\mathrm{P}<0.05$ in bivariate analysis. Backward conditional logistic regression was used with removal of predictors at $\mathrm{P}<0.05$. Odds ratios (OR) and $95 \%$ confidence intervals (CI) were calculated to compare association between detection of Campylobacter species and predictor variables in the study.

\section{Results}

\subsection{Socio-Demographic Characteristics}

A total of 1200 consenting/assenting diarrheal outpatients seeking health care services at the Busia County Hospital were enrolled. The gender distribution was even between male and female (48.1\% vs $51.9 \%)$ with a median age of 3.2 years (age range 1 month to 70.2 years). Patients aged less than 5 years constituted the largest group $(79.6 \%$; 955) and were stratified as $<2$ years $535(44.6 \%), 2$ - 5 years $(442 ; 36.8 \%)$ and the older group $>5$ years $(223 ; 18.6 \%)$. Majority $(62.3 \%)$ of the study subjects were from rural setting (Table 2 ).

\subsection{Prevalence of Campylobacter Species}

The overall prevalence of the Campylobacter species of interest, $C$. jejuni (CJ) and $C$. coli (CC) was $11.6 \%$ from which $C$. jejuni and $C$. coli had $89.2 \%$ and

Table 1. Characteristics of primers used in the study.

\begin{tabular}{|c|c|c|c|c|}
\hline Target species & Primer code & Primer sequence $\left(5^{\prime}-3^{\prime}\right)$ & $\begin{array}{l}\text { Amplicon size } \\
\text { (Bp) }\end{array}$ & Reference \\
\hline \multirow{2}{*}{$\begin{array}{l}\text { Campylabacter } \\
\text { genius. }\end{array}$} & $16 \mathrm{~S}-\mathrm{F}$ & GGAGGCAGCAGTAGGGAATA & \multirow[b]{2}{*}{1062} & \multirow{2}{*}[33]{} \\
\hline & $16 S-R$ & TGACGGGCGGTGAGTACAAG & & \\
\hline \multirow[b]{2}{*}{ C. coli spp } & \multirow[b]{2}{*}{ CC18F CC519R } & GGTATGATTTCTACAAAGCGA & \multirow[b]{2}{*}{500} & \multirow[b]{2}{*}{ [34] } \\
\hline & & ATAAAAGACTATCGTCGCGTG & & \\
\hline \multirow[b]{2}{*}{ C. jejuni $s p p$} & hipO-F & GACTTCGTGCAGATATGGATGCTT & \multirow[b]{2}{*}{344} & \multirow[b]{2}{*}{ [33] } \\
\hline & hipO-R & GCTATAACTATCCGAAGAAGCCATCA & & \\
\hline
\end{tabular}


Table 2. Distribution of Campylobacter infection in diarrheal patients attending Busia County Hospital, Kenya.

\begin{tabular}{cccccc}
\hline \multirow{2}{*}{ Variables } & Positive & Negative & Total & & \\
\cline { 2 - 4 } Age groups & $\mathbf{N}(\%)$ & $\mathbf{N}(\%)$ & $\mathbf{N}(\%)$ & & \\
<2 years & $73(13.7)$ & $462(86.3)$ & $535(44.6)$ & $1.56(0.94,2.6)$ & 0.088 \\
2 - 5 years & $45(10.2)$ & $397(89.8)$ & $442(36.8)$ & $1.04(0.6,1.8)$ & 0.884 \\
$>5$ years & $21(9.4)$ & $202(90.6)$ & $223(18.6)$ & Ref & \\
Gender & & & & & \\
Female & $69(11.1)$ & $554(88.9)$ & $623(51.9)$ & $0.90(0.63,1.28)$ & 0.568 \\
Male & $70(12.1)$ & $507(87.9)$ & $577(48.1)$ & Ref & \\
Residence & & & & & \\
Village & $87(11.6)$ & $661(88.4)$ & $748(62.3)$ & $1.01(0.70,1.46)$ & 0.947 \\
Urban & $52(11.5)$ & $400(88.5)$ & $452(37.7)$ & Ref & \\
\hline
\end{tabular}

OR: Odds ratio, $\mathrm{N}$ : total number of participants, $\mathrm{CI}=$ confidence interval, Ref: Reference.

$10.8 \%$ respectively. The recovery rate of Campylobacter species was relatively higher in children $<2$ years $(13.7 \%)$ as compared to other age groups and showed an overall general progressive downward trend with age (Figure 1). However the difference were not significant $(\mathrm{P}=0.088)($ Table 2$)$.

\subsection{Possible Risk Factors Associated with Campylobacter Infection}

Of all the potential risk variables associated with household practices investigated, higher risk proportions were observed in children $<5$ years. Occupational exposure to poultry farming showed significant association with Campylobacter infection in all the selected group categories of patients with children $<2$ years being 9 times more at risk (OR 9.02; 95\% CI: 3.19 - 25.47, P $<0.001$ ); 2 - 5 years (OR 6.47, 95\% CI: $2.71-15.45, \mathrm{P}<0.001)$ and the older group $>5$ years (OR 10.05; 95\% CI: $2.60-24.29, \mathrm{P}<0.001)$.

Other established age specific household exposure variables significantly associated with Campylobacter infection in children $<2$ years were use of same food cutting board without proper cleaning during food preparation by the mothers/caregivers (OR 3.32, $\mathrm{P}=0.014$ ) however, we noted that regular use of toilets (OR $0.08, \mathrm{P}<0.001$ ) and breast feeding (OR $0.24,<0.001$ ) were protective.

The significant risk variables specific to children between 2 - 5 years included contact with domestic pets (OR 5.72, $\mathrm{P}=0.016)$ and feeding on chicken meat (OR 2.83, $\mathrm{P}=0.007$ ). Generally, it was noted that chicken meat consumption, was the most fed on in this community (78.2\%) followed by fish (74.6\%), Raw milk (70.3\%), eggs (69.3\%), beef (42.5\%) and pork (39.5\%) mainly from local markets (88.6\%) and small hold individual farms (10.2\%). However, urban 


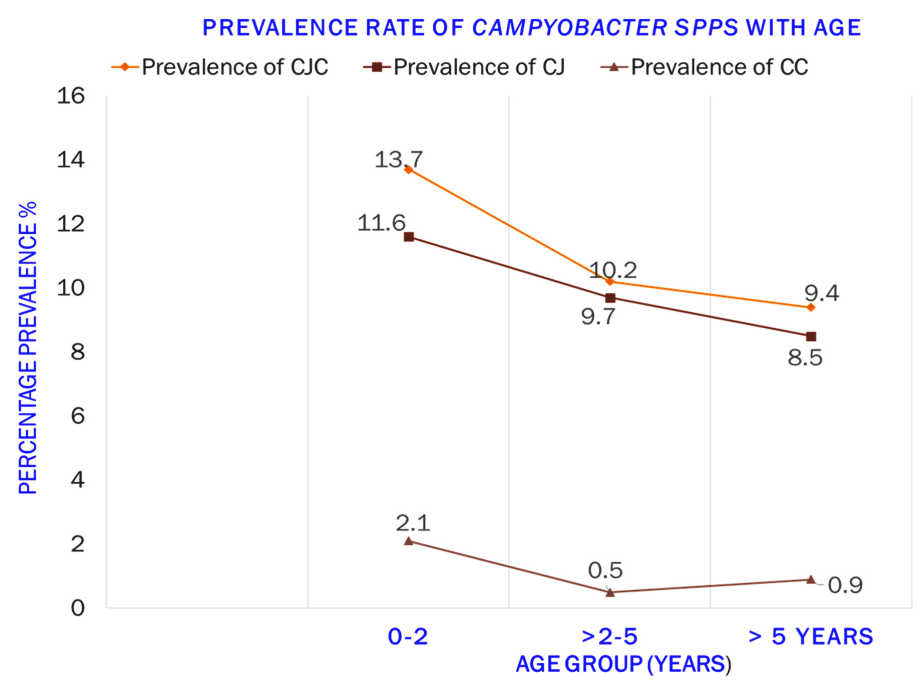

Figure 1. Prevalence of Campylobacter jejuni and C. coli by multiplex PCR from diarrheal children and adults in Busia County Hospital, February, 2017 to April, 2019. Key: CJC; $C$. jejuni and C. coli), CJ; C. jejuni and CC; C. coli.

dwelling was protective ( $\mathrm{OR} 0.47, \mathrm{P}=0.041)$ in this group $(2-5$ years $)$ compared to those from the village.

The most common source of drinking water in this area was borehole (49.5\%) followed by treated tap water from municipality $(28.4 \%)$, river $(20.1 \%)$, pond (1.9\%) with a small percentage from the lake $(0.1 \%)$. Our analysis showed drinking of untreated pond water, an additional significantly risk to children $<5$ years (OR 7.43, $\mathrm{P}<0.001)$ together with female gender (OR 8.25, $\mathrm{P}<0.001$ ). Likewise, we noted specific risk variables in $>5$ years as drinking of raw milk (OR 7.14, $\mathrm{P}=0.001$ ) and contacts with infected (diarrheal) person(s) from the same household (OR 4.72, $\mathrm{P}=0.006$ ) (Table 3).

Among the clinical symptoms of Campylobacter infection analyzed, fever (77.7\%) and vomiting (53.8\%) were the main reported clinical signs. Bivariate analysis revealed that crumps (OR 2.23, P $<0.001$ ), chills (OR 2.77, $\mathrm{P}<0.001$ ) and fatigue (OR $2.37, \mathrm{P}<0.001)$ were significantly associated with the infection in $<5$ years. However, there was no significant $(P>0.05)$ association found at the multivariable level.

The childhood expanded immunization program take up was high $(84.4 \%)$ in this area while very few people $(0.5 \%)$ were under long term medication. The literacy level for the study participants was high with only $9 \%$ reporting no formal education. No significant association $(\mathrm{P}>0.05)$ was found between the level of education of the participants and Campylobacter infections.

The analysis of social economic factors and the participant responses were; type of house lived in (permanent 32.3\%, semi-permanent $60.9 \%$ and thatched $6.8 \%$ ), lighting system used (paraffin $36.3 \%$, electricity $41.0 \%$ and solar $22.7 \%$ ) and the cooking fuel (firewood $44.2 \%$, charcoal $52.8 \%$, paraffin $2.5 \%$, electricity $0.4 \%$ and gas $0.2 \%$ ) in the households. However, none of the above social economic factors were significantly associated with Campylobacter infection. 
Table 3. Campylobacter infection and associated risk factors among the diarrheal patients attending Busia County Hospital, Kenya - February, 2017 to April, 2019.

\begin{tabular}{|c|c|c|c|c|c|c|}
\hline \multirow[b]{2}{*}{ Variables } & \multicolumn{2}{|c|}{$<2$ years } & \multicolumn{2}{|c|}{$2-5$ years } & \multicolumn{2}{|l|}{$>5$ years } \\
\hline & $\begin{array}{c}\text { aOR } 95 \% \\
(L-U)\end{array}$ & P-value & $\begin{array}{c}\text { aOR } 95 \% \\
(\mathrm{~L}-\mathrm{U})\end{array}$ & P-value & $\begin{array}{c}\text { aOR } 95 \% \\
(L-U)\end{array}$ & P-value \\
\hline \multicolumn{7}{|l|}{ Gender } \\
\hline Female & $\begin{array}{c}6.68 \\
(2.51-17.75)\end{array}$ & $<0.001$ & $8.25(3.43-19.81)$ & $<0.001$ & & \\
\hline Male & Ref & & Ref & & & \\
\hline \multicolumn{7}{|l|}{$\begin{array}{l}\text { Occupation of } \\
\text { the respondents }\end{array}$} \\
\hline Business & $2.31(0.82-6.52)$ & 0.114 & $1.3(0.55-3.04)$ & 0.546 & $1.08(0.22-5.14)$ & 0.497 \\
\hline Employed & $0.75(0.22-2.54)$ & 0.645 & $0.95(0.36-2.52)$ & 0.925 & $1.22(0.19-4.08)$ & 0.212 \\
\hline Poultry farming & $9.02(3.19-25.47)$ & $<0.001$ & $6.47(2.71-15.45)$ & $<0.001$ & $10.05(2.60-24.29)$ & $<0.001$ \\
\hline Unemployed & Ref & & Ref & & Ref & \\
\hline \multicolumn{7}{|l|}{$\begin{array}{l}\text { Regular use of } \\
\text { toilet in homestead }\end{array}$} \\
\hline Yes & $0.08(0.02-0.27)$ & $<0.001$ & & & & \\
\hline No & Ref & & & & & \\
\hline \multicolumn{7}{|l|}{$\begin{array}{c}\text { Source of } \\
\text { drinking water }\end{array}$} \\
\hline Borehole & $1.46(0.55-3.84)$ & 0.447 & $1.22(0.61-2.44)$ & 0.185 & & \\
\hline Lake water & UD & UD & UD & UD & & \\
\hline Pond water & $7.43(1.70-16.33)$ & $<0.001$ & $6.51(1.57-13.59)$ & 0.001 & & \\
\hline River water & $2.90(0.92-7.70)$ & 0.058 & $3.47(0.62-7.19)$ & 0.063 & & \\
\hline Tap water & Ref & & Ref & & & \\
\hline \multicolumn{7}{|l|}{ Breast milk feeding } \\
\hline Yes & $0.24(0.11-0.52)$ & $<0.001$ & & & & \\
\hline No & Ref & & & & & \\
\hline \multicolumn{7}{|l|}{$\begin{array}{l}\text { Repeated use of } \\
\text { same food cutting } \\
\text { board without } \\
\text { soap wash in } \\
\text { household kitchen }\end{array}$} \\
\hline Yes & $3.32(1.28-8.62)$ & 0.014 & & & & \\
\hline No & Ref & & & & & \\
\hline \multicolumn{7}{|l|}{ Residence } \\
\hline Urban & & & $0.47(0.20-0.82)$ & 0.041 & & \\
\hline Village & & & Ref & & & \\
\hline
\end{tabular}




\section{Continued}

\section{Contact with domestic pets in the house}

Yes

Not sure

No

Eating chicken meat

Yes

No

Drinking raw milk

Yes

No

Contact with

infected diarrheal

person(s) in the

same homestead

10 days before

onset of diarrhea

Yes

Not sure
$5.72(1.21-10.04) \quad 0.016$

UD UD

Ref

$2.83(1.32-6.04) \quad 0.007$

Ref
$7.14(1.96-18.24) \quad 0.001$
Ref

No

$4.72(2.10-10.52)$

0.006

UD

0.999

aOR: Adjusted Odds Ratio, L: Lower limit, U: Upper, P value: Probability value, Ref: Reference, UD: Undefined.

\section{Discussion}

In this study, the high number of hospital visits from children $<5$ years of age (81.4\%) suggests diarrhea, which Campylobacter is mostly associated with, was largely a pediatric disease in this region.

Our overall prevalence of Campylobacter infection among diarrheal patients was $11.6 \%$, comprising of $89.2 \%$ C. jejuni and $10.8 \%$ C. coli. This prevalence was higher compared to reports from studies in Nairobi 3.1\% [31] and Kisii 5.8\% [35] in Kenya, Tanzania 9.3\% [36] and Egypt 9\% [20], consistent to those reported from Ethiopia 11.6\% [37], and lower than those found in Nigeria 16.5\% [38] and Algeria 17.7\% [39]. These variations may arise due to differences in the set predictive values of test systems, social and cultural practices, geographical location, population immunity as well as differences in public health standards, intervention strategies, surveillance systems, food safety practices, and the prevalence of Campylobacter in natural reservoirs in different regions [23] [40].

From an African perspective, where Campylobacter is endemic and chicken meat on top feeding list, our reported prevalence $(11.6 \%)$ in human is considered significant especially in this era of HIV/AIDS. Although this study was li- 
mited in establishing the role of HIV in Campylobacter infection, it is important to consider Campylobacter infection in a different perspective because of its close association with HIV/AIDS. Studies have predicted an upsurge of several diseases associated with immune-suppression and reported incidences of Campylobacter infection in patients with HIV/AIDS as 39 times higher than the infection rate in the general population [41]. There might be a possible future increase of Campylobacter infection since HIV infection has been reported high (7.7\%) in this area with an incidence of 52,800 cases across all ages annually [42].

Although the diagnosis and treatment of diarrhea was not captured in our questionnaire, the health management strategies adopted by the Ministry of Health $(\mathrm{MoH})$ Kenya since 2010 on appropriate measures for treatment and management of diarrheal diseases both in hospitals and home based care at community level recommends ORS and Zinc for mild diarrhea. Antibiotics are rarely given unless in severe cases of dysentery, cholera, giardiasis and amoebiasis. Detection of these diarrheal etiologies require proper laboratory systems which are absent in most hospitals in Buisa and most patients are treated empirically [43].

Even though there was a general downward trend of prevalence of Campylobacter infection from children $<2$ years $(13.7 \%)$ through $2-5$ years $(10.2 \%)$ and $>5$ years $(9.4 \%)$, this general progressive decline of the infection with age might be due to age-related acquisition of protective immunity as a result of close proximity and frequent interactions with livestock hence frequent exposure to Campylobacter infection [17] [18] [43]. However, other studies have shown a decline of this immunity at an advanced age $>60$ years [44].

This study analyzed the potential risk exposures associated with household practices from several exposure variables of social demographic, clinical, economic and behavioral factors considered on the basis of biological plausibility and previous knowledge on the risks associated with Campylobacter infection [13] [20] [21]. Our findings suggest that homestead practices of poultry farming, eating chicken meat, drinking raw milk, breast feeding, use of untreated pond water, contact with infected diarrheal individuals and domestic pets, use of same food cutting board without washing with soap, use of toilets, residential area and gender were significantly associated with human Campylobacter infection in Busia County. Although this study did not comprehensively evaluate all the plausible social economic factors, the few that were analyzed did not yield any significant association with Campylobacter infection.

Majority of the participants presented with fever (77.7\%) and vomiting (53.8\%) as the main clinical signs. Similarly none of the analyzed clinical signs and symptoms were found to be associated with Campylobacter infection. This is likely because majority of Campylobacter infections in low resource settings are mainly asymptomatic [22].

Poultry farming was significantly associated with Campylobacter infection across all age divide of the participants. This might be because of the fact that 
most of the household livelihoods in Busia County where the study was conducted, depend majorly on livestock farming with chicken being the most commonly kept livestock that offers quick sale and food in an environment where water sanitation and hygiene (WASH) pose a lot of challenges in the livestock sector [29]. Campylobacter enters food chain through poultry regarded as the main source through which transmissions occur and once established in chicken caeca, the number proliferates rapidly to high levels (109 CFU/g) and can remain carriers until slaughter [45] [46]. During this period, high number of Campylobacter are shaded through feces and contaminates the surrounding environment where the birds live and in turn, allow the pathogen transmission to humans through fecal oral rout [47]. Likewise, there has been increasing evidence that contact with farm animals offer significant risk exposures to human Campylobacter infection [13] [48] with poultry being the major source of food-related transmission and reservoir of Campylobacter species to humans [49]. In addition, source-attribution studies have linked zoonotic transmission of human Campylobacter to poultry exposures and consumption of chicken, dairy products and contaminated water [13] [14] [17].

We noted at the same time that household use and drinking of untreated pond water was a significant risk for Campylobacter infection among children < 5 years. This environmental surface water (pond) is served by several contaminated streams from free-range small hold livestock farm systems and can remain stagnant for a long period of time. Consequently such cumulative contamination by Campylobacter species may present potential reservoir and transmitting vehicles for Campylobacter [50] [51] [52] [53]. Studies have shown many possible sources of Campylobacter infection in humans including contaminated water [54]. In Kenya, approximately 17,100 children under 5 years die each year from diarrhea, with $90 \%$ of these deaths being attributed to poor water, sanitation and hygiene [55]. According to Busia County Development Plan, 2018-2022, the main source of drinking water is from borehole (46\%), other sources including springs, rivers, piped and pond water. Apart from urban treated water supplied by Busia Water and Sewerage Company with a supply capacity of only $12.5 \%$, the larger percentage of water used is untreated. Mothers or caregivers possibly struggle for clean and safe water in this area and a number of them likely end up using untreated pond water to care for children whose immunity may have not developed as much.

Female children $<5$ years were more at risk of Campylobacter infection. Similarly, studies on diarrheal correlates associated with enteric bacterial infections in Busia and Muranga Counties in Kenya showed that female between 6 36 months were twice more likely to be infected with enteric bacterial pathogens than their male counterparts [56] [57]. Likewise in rural Sudan, female children $<5$ years were more at risk [58]. Although female subjects were found to be significantly more at risk of Campylobacter infections, other studies have contrasting reports with unclear reasons [59] [60]. Sex specific age differences in immunity may exist but have not been elaborately documented. More investiga- 
tions are recommended for better understanding on factors such as immunological, demographic and behavioral associated with sex specific differences across the globe.

Although we did not directly assess the risk associated with each and every step in handling and preparation of food in household kitchens, assessment of use of same food cutting board without proper wash was picked as a significant risk for children $<2$ years. Care givers involved in food preparation for these children were three times ( $A O R 3.32, \mathrm{P}=0.014$ ) more likely to predispose their children to Campylobacter infection and this is consistent with other findings [61]. In Kenya, complementary feeding is introduced after 6 months though some mothers introduce weaning earlier. It is possible that there might have been lack of personal hygiene and inadequate cleansing of food surfaces by the mothers or caregivers and subsequent cross-contamination of Campylobacter during food preparation from raw food. Similarly, it has been shown that unhygienic food preparation, food storage and subsequent feeding of infants can aggravate transmission of diarrheal pathogens and pose great risk to this age cohort [62]. Otherwise self-contamination and cross transmission of Campylobacter infection may be minimize through personal and kitchen hygiene practices at household level.

Breast feeding and frequent use of toilet had protective effect among children $<2$ years. This might be due to transfers of maternal antibodies in breast milk with health befits to the child. Open defecation predisposes water and food to fecal contamination more so when it rains and may increase the risk of Campylobacter transmission. Frequent use of toilets partly takes care of this public health problem and ensures standards necessary to break the vicious cycle of diarrheal pathogens spread from persons infected to the environment hence minimize the transmission of Campylobacter infection and offer protection to these children [39]. In addition, this study found a fairly high literacy level among the participants with $91 \%$ having at least acquired primary school education. This may have contributed towards adherence to the recommended WASH practices such as frequent usage of toilets.

Many people keep cats and dogs at home as pets and for security reasons and our study showed this interaction was significantly associated with Campylobacter infection in children of $2-5$ years (OR 5.72, $\mathrm{P}=0.016$ ). This might have been due to their playful nature at this age and a likelihood of being physically closer to these pets and more likely than others to contaminate and put their fingers or other items into their mouths which might have aggravated the transmission of the infection. Our finding is similar to previous studies performed in Kenya [63] which showed that the incident of Campylobacter infection was significantly higher in children who had contact with domestic animals and more so in those who keep dogs and cats as pets [64].

On dietary habits reported at household level, consumption of chicken was more frequent $(78.2 \%)$ of all the foods considered and was significantly associated with Campylobacter infection in children of $2-5$ years. This age is ex- 
plorative, very playful and is common when self-feeding practices occur with subsequent development of immunity due to exposures. When chicken is prepared under unhygienic way or consumed when under-cooked, it can cause Campylobacter infection and is considered the most common cause of diarrheal outbreaks in Europe [65]. Although Campylobacter infection rate was the same among rural and urban dwellers, children between 2 - 5 years of age from urban were more protected from the infection $0.47(0.20-0.82) \mathrm{P}=0.041$ as compared to those from rural. The expected improved environment and water, sanitation and hygiene (WASH) infrastructure in urban areas may have played a role and came with health benefits to these children [66].

Drinking raw milk was the third most used food item at home $(70.3 \%)$ and was a risk in $>5$ years. Raw unpasteurized milk has largely been implicated in several Campylobacter infection and outbreaks [67] [68] [69]. Elsewhere, genomic analyses showed that the presence of Campylobacter species in milk was attributed to fecal contamination [70].

We found exposure to household member with diarrhea a risk to those $>5$ years of age ( $\mathrm{AOR} 4.72, \mathrm{P}=0.006$ ). The mode of transmission here is thought to be through fecal-oral root from either person-to-person or exposure to a common source of infection within the homestead not connected to the exposures under investigation. We could not establish information about the exposures to risk factors associated with other household members in our study. However, similar studies have implicated the contributions of person-to-person transmission of Campylobacter infection and outbreaks [65] [71].

The absence of association between Campylobacter infection and clinical symptoms has been reported in low income countries [72] [73]. This may be due to development of defensive immunity characterized with developing countries, high sensitivity of the PCR method in detecting low number of live and dead bacteria, all of which are neither indicative of clinical disease. Furthermore, the detected Campylobacter can also reflect convalescent phase as excretion of Campylobacter may last up to 10 weeks after infection [17]. Other factors considered without significant association included medical history on expanded immunization program (EIP) vaccine coverage, education, contact with wildlife, local and or International travel, types of house lived in and any long term medication and immunosuppressive treatment based on a 4-week history.

\section{Conclusion}

The present study found that diarrhea is mainly a pediatric disease and children $<5$ years are more predisposed to homestead related risk activities associated with Campylobacter infection. Campylobacter jejuni was found to be the leading cause of Campylobacter infections in the study area. Ruling out Campylobacter infection in patients with diarrhea would help in proper management more so in children who are most affected, and where HIV prevalence is high as in most developing countries. Personal hygiene practices and proper animal husbandry 
especially where livestock-human interaction is common is important. Further studies are required on sex specific age difference, social economic factors and the role played by the environment and other domestic animals in the transmission of Campylobacter infection. This would advance knowledge and understanding on source attribution and transmission dynamics for effective control and management of the infection.

\section{Acknowledgements}

We wish to thank the patients and County health officials for their cooperation during the study period. We appreciate the entire clinical and laboratory staff both in Busia County Hospital, Centre for Microbiology Research, Nairobi and International Livestock Research Institute Busia for their hard work and diligence in supporting this study. We thank the Director General KEMRI for partly funding this study through the Internal Research Grant (IRG-Ref. No. KEMRI/ CONF/FIN/6/101).

\section{Data Availability}

The datasets used and analyzed during this study are available from the corresponding author on request.

\section{Ethical Consideration}

The study was approved by the Scientific Ethical Review Unit (SERU), Kenya Medical Research Institute (KEMRI protocol No. 3320). Permission was obtained from County Health offices and Hospital administrators. Written informed consent was obtained from the study patients or guardians of minors/study patients. The results were shared with the duty physician for appropriate patient treatment and management.

\section{Conflicts of Interest}

No author has any competing interest to declare.

\section{References}

[1] Randall, L., Ridley, A., Cooles, S., Sharma, M., Sayers, A., Pumbwe, L., Newell, D., Piddock, L. and Woodward, M.J. (2003) Prevalence of Multiple Antibiotic Resistance in 443 Campylobacter spp. Isolated from Humans and Animals. Journal of Antimicrobial Chemotherapy, 52, 507-510. https://doi.org/10.1093/jac/dkg379

[2] Coker, A.O., Isokpehi, R.D., Thomas, B.N., Amisu, K.O. and Obi, C.L. (2002) Human Campylobacteriosis in Developing Countries-Synopsis-Statistical Data Included. Emerging Infectious Diseases, 8, 237-243. https://doi.org/10.3201/eid0803.010233

[3] Sáenz, Y., Zarazaga, M., Lantero, M., Gastañares, M.J., Baquero, F. and Torres, C. (2000) Antibiotic Resistance in Campylobacterstrains Isolated from Animals, Foods, and Humans in Spain in 1997-1998. Antimicrobial Agents and Chemotherapy, 44, 267-271. https://doi.org/10.1128/AAC.44.2.267-271.2000

[4] Helwigh, B. and Korsgaard, H. (2007) The Community Summary Report on Trends 
and Sources of Zoonoses, Zoonotic Agents, Antimicrobial Resistance and Foodborne Outbreaks in the European Union in 2006. European Food Safety Authority, Parma.

[5] Murray, C.J., Vos, T., Lozano, R., Naghavi, M., Flaxman, A.D., Michaud, C., Ezzati, M., Shibuya, K., Salomon, J.A. and Abdalla, S. (2012) Disability-Adjusted Life Years (DALYs) for 291 Diseases and Injuries in 21 Regions, 1990-2010: A Systematic Analysis for the Global Burden of Disease Study 2010. The Lancet, 380, 2197-2223. https://doi.org/10.1016/S0140-6736(12)62134-5

[6] Mageto, L., Ombui, J. and Mutua, F. (2018) Prevalence and Risk Factors for Campylobacter Infection of Chicken in Peri-Urban Areas of Nairobi Kenya. Journal of Dairy, Veterinary \& Animal Research, 7, 22-27. https://doi.org/10.15406/jdvar.2018.07.00184

[7] Man, S.M. (2011) The Clinical Importance of Emerging Campylobacter Species. Nature Reviews Gastroenterology \& Hepatology, 8, 669.

https://doi.org/10.1038/nrgastro.2011.191

[8] World Health Organization (2013) The Global View of Campylobacteriosis: Report of an Expert Consultation. Utrecht.

[9] Skirrow, M.B. and Blaser, M.J. (2000) Clinical Aspects of Campylobacter Infection. In: Nachamkin, I. and Blaser, M.J., Eds., Campylobacter, American Society for Microbiology, Washington DC, 69-88.

[10] Butzler, J.-P. and Oosterom, J. (1991) Campylobacter: Pathogenicity and Significance in Foods. International Journal of Food Microbiology, 12, 1-8. https://doi.org/10.1016/0168-1605(91)90043-O

[11] Acheson, D. and Allos, B.M. (2001) Campylobacter jejuni Infections: Update on Emerging Issues and Trends. Clinical Infectious Diseases, 32, 1201-1206. https://doi.org/10.1086/319760

[12] Griffiths, P. and Park, R. (1990) Campylobacters Associated with Human Diarrhoeal Disease. Journal of Applied Bacteriology, 69, 281-301. https://doi.org/10.1111/j.1365-2672.1990.tb01519.x

[13] Domingues, A., Pires, S.M., Halasa, T. and Hald, T. (2012) Source Attribution of Human Campylobacteriosis Using a Meta-Analysis of Case-Control Studies of Sporadic Infections. Epidemiology \& Infection, 140, 970-981. https://doi.org/10.1017/S0950268811002676

[14] European Food Safety Authority; European Centre for Disease Prevention and Control (2015) The European Union Summary Report on Trends and Sources of Zoonoses, Zoonotic Agents and Food-Borne Outbreaks in 2014. EFSA Journal, 13, 4329. https://doi.org/10.2903/j.efsa.2015.4329

[15] Miller, W.G. and Mandrell, R.E. (2005) Prevalence of Campylobacter in the Food and Water Supply: Incidence, Outbreaks, Isolation and Detection. In: Ketley, J. and Konkel, M.E., Eds., Campylobacter jejuni: New Perspectives in Molecular and Cellular Biology, Horizon Scientific Press, Norfolk, 101-163.

[16] Allos, B. and Blaser, M. (2010) Campylobacter jejuni and Related Species. In: Principles and Practice of Infectious Diseases, 7th Edition, Elsevier Churchill Livingstone, Philadelphia, 2793-2802.

https://doi.org/10.1016/B978-0-443-06839-3.00216-2

[17] Havelaar, A.H., van Pelt, W., Ang, C.W., Wagenaar, J.A., van Putten, J.P., Gross, U. and Newell, D.G. (2009) Immunity to Campylobacter: Its Role in Risk Assessment and Epidemiology. Critical Reviews in Microbiology, 35, 1-22.

https://doi.org/10.1080/10408410802636017 
[18] Janssen, R., Krogfelt, K.A., Cawthraw, S.A., van Pelt, W., Wagenaar, J.A. and Owen, R.J. (2008) Host-Pathogen Interactions in Campylobacter Infections: The Host Perspective. Clinical Microbiology Reviews, 21, 505-518. https://doi.org/10.1128/CMR.00055-07

[19] Humphrey, T., O'Brien, S. and Madsen, M. (2007) Campylobacters as Zoonotic Pathogens: A Food Production Perspective. International Journal of Food Microbiology, 117, 237-257. https://doi.org/10.1016/j.ijfoodmicro.2007.01.006

[20] Rao, M.R., Naficy, A.B., Savarino, S.J., Abu-Elyazeed, R., Wierzba, T.F., Peruski, L.F., Abdel-Messih, I., Frenck, R. and Clemens, J.D. (2001) Pathogenicity and Convalescent Excretion of Campylobacter in Rural Egyptian Children. American Journal of Epidemiology, 154, 166-173. https://doi.org/10.1093/aje/154.2.166

[21] Hassan, K.E., Mansour, A., Shaheen, H., Amine, M., Riddle, M.S., Young, S.Y., Sebeny, P. and Levin, S. (2014) The Impact of Household Hygiene on the Risk of Bacterial Diarrhea among Egyptian Children in Rural Areas, 2004-2007. The Journal of Infection in Developing Countries, 8, 1541-1551. https://doi.org/10.3855/jidc.4539

[22] Kaakoush, N.O., Castaño-Rodríguez, N., Mitchell, H.M. and Man, S.M. (2015) Global Epidemiology of Campylobacter Infection. Clinical Microbiology Reviews, 28, 687-720. https://doi.org/10.1128/CMR.00006-15

[23] Sadkowska-Todys, M. and Kucharczyk, B. (2012) Campylobacteriosis in Poland in 2010. Przeglad Epidemiologiczny, 66, 255-258.

[24] Oberhelman, R.A. and Taylor, D.N. (2000) Campylobacter Infections in Developing Countries. In: Nachamkin, I. and Blasér, M., Eds., Campylobacter, 2nd Edition, ASM Press, Washington DC, 139-153.

[25] Blaser, M.J., Taylor, D.N. and Feldman, R.A. (1983) Epidemiology of Campylobacter jejuni Infections. Epidemiologic Reviews, 5, 157-176.

https://doi.org/10.1093/oxfordjournals.epirev.a036256

[26] Jacob, P., Mdegela, R.H. and Nonga, H.E. (2011) Comparison of Cape Town and Skirrow's Campylobacter Isolation Protocols in Humans and Broilers in Morogoro, Tanzania. Tropical Animal Health and Production, 43, 1007-1013. https://doi.org/10.1007/s11250-011-9799-Z

[27] Wamola, I., Mirza, N., Ngugi, J. and Bwibo, N. (1983) Campylobacter Gastroenteritis in Nairobi. East African Medical Journal, 60, 146-149.

[28] Fèvre, E.M., de Glanville, W.A., Thomas, L.F., Cook, E.A., Kariuki, S. and Wamae, C.N. (2017) An Integrated Study of Human and Animal Infectious Disease in the Lake Victoria Crescent Small-Holder Crop-Livestock Production System, Kenya. BMC Infectious Diseases, 17, 457. https://doi.org/10.1186/s12879-017-2559-6

[29] Omusotsi, O.G., Dennis, A.T., Kilimo, C.J., Alex, M., Kipchirchir, K.K., Cynthia, J., Mercy, L., Oloo, N.W. and Ogutu, K.F. (2019) Assessing the Social, Cultural, Economic and Environmental Conditions of Nambale Town in Busia County, Kenya. Urban and Regional Planning, 4, 16. https://doi.org/10.11648/j.urp.20190401.13

[30] Nasrin, D., Wu, Y., Blackwelder, W.C., Farag, T.H., Saha, D., Sow, S.O., Alonso, P.L., Breiman, R.F., Sur, D. and Faruque, A.S. (2013) Health Care Seeking for Childhood Diarrhea in Developing Countries: Evidence from Seven Sites in Africa and Asia. The American Journal of Tropical Medicine and Hygiene, 89, 3-12. https://doi.org/10.4269/ajtmh.12-0749

[31] Corry, J.E., Atabay, H.I., Forsythe, S.J. and Mansfield, L.P. (2003) Culture Media for the Isolation of Campylobacters, Helicobacters and Arcobacters. In: Progress in Industrial Microbiology, Elsevier, Amsterdam, 271-316. https://doi.org/10.1016/S0079-6352(03)80021-8 
[32] Bang, D.D., Nielsen, E., Knudsen, K. and Madsen, M. (2003) A One-Year Study of Campylobacter Carriage by Individual Danish Broiler Chickens as the Basis for Selection of Campylobacter spp. Strains for a Chicken Infection Model. Epidemiology \& Infection, 130, 323-333. https://doi.org/10.1017/S095026880200821X

[33] Linton, D., Owen, R. and Stanley, J. (1996) Rapid Identification by PCR of the Genus Campylobacter and of Five Campylobacter Species Enteropathogenic for Man and Animals. Research in Microbiology, 147, 707-718. https://doi.org/10.1016/S0923-2508(97)85118-2

[34] Turkson, P.K., Lindqvist, K.J. and Kapperud, G. (1988) Isolation of Campylobacter spp. and Yersinia enterocolitica from Domestic Animals and Human Patients in Kenya. Apmis, 96, 141-146. https://doi.org/10.1111/j.1699-0463.1988.tb05281.x

[35] Swierczewski, B.E., Odundo, E.A., Koech, M.C., Ndonye, J.N., Kirera, R.K., Odhiambo, C.P., Cheruiyot, E.K., Shaffer, D.N., Ombogo, A.N. and Oaks, E.V. (2013) Enteric Pathogen Surveillance in a Case-Control Study of Acute Diarrhoea in the Town of Kisii, Kenya. Journal of Medical Microbiology, 62, 1774-1776. https://doi.org/10.1099/jmm.0.059139-0

[36] Mdegela, R., Nonga, H., Ngowi, H. and Kazwala, R. (2006) Prevalence of Thermophilic Campylobacter Infections in Humans, Chickens and Crows in Morogoro, Tanzania. Journal of Veterinary Medicine, Series B, 53, 116-121.

https://doi.org/10.1111/j.1439-0450.2006.00926.x

[37] Beyene, G. and Haile-Amlak, A. (2004) Antimicrobial Sensitivity Pattern of Campylobacter Species among Children in Jimma University Specialized Hospital, Southwest Ethiopia. Ethiopian Journal of Health Development, 18, 185-189. https://doi.org/10.4314/ejhd.v18i3.9958

[38] Coker, A. and Adefeso, A. (1994) The Changing Patterns of Campylobacter jejunilcoli in Lagos, Nigeria after Ten Years. East African Medical Journal, 71, 437-440.

[39] Lengerh, A., Moges, F., Unakal, C. and Anagaw, B. (2013) Prevalence, Associated Risk Factors and Antimicrobial Susceptibility Pattern of Campylobacter Species among under Five Diarrheic Children at Gondar University Hospital, Northwest Ethiopia. BMC Pediatrics, 13, 82. https://doi.org/10.1186/1471-2431-13-82

[40] Kubota, K., Kasuga, F., Iwasaki, E., Inagaki, S., Sakurai, Y., Komatsu, M., Toyofuku, H., Angulo, F.J., Scallan, E. and Morikawa, K. (2011) Estimating the Burden of Acute Gastroenteritis and Foodborne Illness Caused by Campylobacter, Salmonella, and Vibrio parahaemolyticus by Using Population-Based Telephone Survey Data, Miyagi Prefecture, Japan, 2005 to 2006. Journal of Food Protection, 74, 1592-1598. https://doi.org/10.4315/0362-028X.JFP-10-387

[41] Altekruse, S.F., Stern, N.J., Fields, P.I. and Swerdlow, D.L. (1999) Campylobacter jejuni-An Emerging Foodborne Pathogen. Emerging Infectious Diseases, 5, 28. https://doi.org/10.3201/eid0501.990104

[42] Makwaga, O., Adhiambo, M., Mulama, D.H., Muoma, J., Adungo, F., Wanjiku, H., Ongaya, A., Maitha, G.M. and Mwau, M. (2020) Prevalence of Human Immunodeficiency Virus-1 Drug-Resistant Mutations among Adults on First- and Second-Line Antiretroviral Therapy in a Resource-Limited Health Facility in Busia County, Kenya. The Pan African Medical Journal, 37, 311. https://doi.org/10.11604/pamj.2020.37.311.25909

[43] Mulatya, D.M. and Ochieng, C. (2020) Disease Burden and Risk Factors of Diarrhoea in Children under Five Years: Evidence from Kenya's Demographic Health Survey 2014. International Journal of Infectious Diseases, 93, 359-366. https://doi.org/10.1016/j.ijid.2020.02.003 
[44] Levesque, S., Fournier, E., Carrier, N., Frost, E., Arbeit, R.D. and Michaud, S. (2013) Campylobacteriosis in Urban versus Rural Areas: A Case-Case Study Integrated with Molecular Typing to Validate Risk Factors and to Attribute Sources of Infection. PLOS ONE, 8, e83731. https://doi.org/10.1371/journal.pone.0083731

[45] Taha-Abdelaziz, K., Yitbarek, A., Alkie, T.N., Hodgins, D.C., Read, L.R., Weese, J.S. and Sharif, S. (2018) PLGA-Encapsulated CpG ODN and Campylobacter jejuni Lysate Modulate Cecal Microbiota Composition in Broiler Chickens Experimentally Challenged with C. jejuni. Scientific Reports, 8, Article No. 12076.

https://doi.org/10.1038/s41598-018-30510-w

[46] Newell, D., Elvers, K., Dopfer, D., Hansson, I., Jones, P., James, S., Gittins, J., Stern, N., Davies, R. and Connerton, I. (2011) Biosecurity-Based Interventions and Strategies to Reduce Campylobacter spp. on Poultry Farms. Applied and Environmental Microbiology, 77, 8605-8614. https://doi.org/10.1128/AEM.01090-10

[47] Goni, M., Muhammad, I., Goje, M., Abatcha, M., Bitrus, A. and Abbas, M. (2017) Campylobacter in Dogs and Cats; Its Detection and Public Health Significance: A Review. Advances in Animal and Veterinary Sciences, 5, 239-248. https://doi.org/10.5455/javar.2018.e267

[48] Kownhar, H., Muthu Shankar, E., Rajan, R., Vengatesan, A. and Rao, U.A. (2007) Prevalence of Campylobacter jejuni and Enteric Bacterial Pathogens among Hospitalized HIV Infected versus Non-HIV Infected Patients with Diarrhoea in Southern India. Scandinavian Journal of Infectious Diseases, 39, 862-866. https://doi.org/10.1080/00365540701393096

[49] Ijaz, U.Z., Sivaloganathan, L., McKenna, A., Richmond, A., Kelly, C., Linton, M., Stratakos, A.C., Lavery, U., Elmi, A. and Wren, B.W. (2018) Comprehensive Longitudinal Microbiome Analysis of the Chicken Cecum Reveals a Shift from Competitive to Environmental Drivers and a Window of Opportunity for Campylobacter. Frontiers in Microbiology, 9, 2452. https://doi.org/10.3389/fmicb.2018.02452

[50] Taylor, D.N., Brown, M. and McDermott, K.T. (1982) Waterborne Transmission of Campylobacter Enteritis. Microbial Ecology, 8, 347-354.

https://doi.org/10.1007/BF02010674

[51] Aho, M., Kurki, M., Rautelin, H. and Kosunen, T. (1989) Waterborne Outbreak of Campylobacter Enteritis after Outdoors Infantry Drill in Utti, Finland. Epidemiology \& Infection, 103, 133-141. https://doi.org/10.1017/S0950268800030430

[52] Hänninen, M.-L., Haajanen, H., Pummi, T., Wermundsen, K., Katila, M.-L., Sarkkinen, H., Miettinen, I. and Rautelin, H. (2003) Detection and Typing of Campylobacter jejuni and Campylobacter coli and Analysis of Indicator Organisms in Three Waterborne Outbreaks in Finland. Applied and Environmental Microbiology, 69, 1391-1396. https://doi.org/10.1128/AEM.69.3.1391-1396.2003

[53] Richardson, G., Thomas, D.R., Smith, R., Nehaul, L., Ribeiro, C., Brown, A. and Salmon, R. (2007) A Community Outbreak of Campylobacter jejuni Infection from a Chlorinated Public Water Supply. Epidemiology \& Infection, 135, 1151-1158. https://doi.org/10.1017/S0950268807007960

[54] Abe, T., Haga, S., Yokoyama, K. and Watanabe, N. (2008) An Outbreak of Campylobacter jejuni subsp. jejuni Infection via Tap Water. Japanese Journal of Infectious Diseases, 61, 327.

[55] Bartram, J. (2003) New Water Forum Will Repeat Old Message. Bulletin of the World Health Organization, 81, 158.

[56] Onyango, D. and Angienda, P. (2010) Epidemiology of Waterborne Diarrhoeal Diseases among Children Aged 6 - 36 Months Old in Busia-Western Kenya. 
[57] Mbuthia, O.W. (2019) Diarrheal Correlates Associated with Enteric Bacterial Infections among Children below Five Years in Murang'a County, Kenya. The Pan African Medical Journal, 34, 170. https://doi.org/10.11604/pamj.2019.34.170.17403

[58] El Samani, F.Z., Willett, W.C. and Ware, J.H. (1989) Predictors of Simple Diarrhoea in Children under 5 Years-A Study of a Sudanese Rural Community. Social Science \& Medicine, 29, 1065-1070. https://doi.org/10.1016/0277-9536(89)90017-8

[59] Strachan, N., et al. (2008) Sexual Dimorphism in Campylobacteriosis. Epidemiology \& Infection, 136, 1492-1495.

[60] Kapperud, G. and Aasen, S. (1992) Descriptive Epidemiology of Infections Due to Thermotolerant Campylobacter spp. in Norway, 1979-1988. APMIS, 100, 883-890. https://doi.org/10.1111/j.1699-0463.1992.tb04014.x

[61] Little, C., Gormley, F., Rawal, N. and Richardson, J. (2010) A Recipe for Disaster: Outbreaks of Campylobacteriosis Associated with Poultry Liver Pâté in England and Wales. Epidemiology \& Infection, 138, 1691-1694. https://doi.org/10.1017/S0950268810001974

[62] Mbugua, S., Musikoyo, E., Ndungi, F., Sang, R., Kamau-Mbuthia, E. and Ngotho, D. (2014) Determinants of Diarrhea among Young Children under the Age of Five in Kenya, Evidence from KDHS 2008-09. African Population Studies, 28, 1046-1056. https://doi.org/10.11564/28-0-556

[63] Conan, A., O’Reilly, C.E., Ogola, E., Ochieng, J.B., Blackstock, A.J., Omore, R., Ochieng, L., Moke, F., Parsons, M.B. and Xiao, L. (2017) Animal-Related Factors Associated with Moderate-to-Severe Diarrhea in Children Younger than Five Years in Western Kenya: A Matched Case-Control Study. PLoS Neglected Tropical Diseases, 11, e0005795. https://doi.org/10.1371/journal.pntd.0005795

[64] Westermarck, E. (2016) Chronic Diarrhea in Dogs: What Do We Actually Know about It? Topics in Companion Animal Medicine, 31, 78-84.

https://doi.org/10.1053/j.tcam.2016.03.001

[65] Greig, J.D. and Ravel, A. (2009) Analysis of Foodborne Outbreak Data Reported Internationally for Source Attribution. International Journal of Food Microbiology, 130, 77-87. https://doi.org/10.1016/j.ijfoodmicro.2008.12.031

[66] Hassan, A., Abdualbaki, A. and Khald, A. (2007) Epidemiology, Clinical Features and Antibiotic Susceptibility of Campylobacter Infections in Sanaa, Yemen. Journal of Chinese Clinical Medicine, 2, 445-463.

[67] Weltman, A., Longenberger, A.H., Moll, M., Johnson, L., Martin, J. and Beaudoin, A. (2013) Recurrent Outbreak of Campylobacter jejuni Infections Associated with a Raw Milk Dairy-Pennsylvania, April-May 2013. MMWR. Morbidity and Mortality Weekly Report, 62, 702.

[68] Castrodale, L., Gerlach, R., Xavier, C., Smith, B., Cooper, M. and McLaughlin, J. (2013) Sharing Milk But Not Messages: Campylobacteriosis Associated with Consumption of Raw Milk from a Cow-Share Program in Alaska, 2011. Journal of Food Protection, 76, 744-747. https://doi.org/10.4315/0362-028X.JFP-12-329

[69] Longenberger, A.H., Palumbo, A.J., Chu, A.K., Moll, M.E., Weltman, A. and Ostroff, S.M. (2013) Campylobacter jejuni Infections Associated with Unpasteurized Milk-Multiple States, 2012. Clinical Infectious Diseases, 57, 263-266. https://doi.org/10.1093/cid/cit231

[70] Revez, J., Zhang, J., Schott, T., Kivistö, R., Rossi, M. and Hänninen, M.-L. (2014) Genomic Variation between Campylobacter jejuni Isolates Associated with MilkBorne-Disease Outbreaks. Journal of Clinical Microbiology, 52, 2782-2786. 
https://doi.org/10.1128/JCM.00931-14

[71] Vally, H., Glass, K., Ford, L., Hall, G., Kirk, M.D., Shadbolt, C., Veitch, M., Fullerton, K.E., Musto, J. and Becker, N. (2014) Proportion of Illness Acquired by Foodborne Transmission for Nine Enteric Pathogens in Australia: An Expert Elicitation. Foodborne Pathogens and Disease, 11, 727-733.

https://doi.org/10.1089/fpd.2014.1746

[72] Randremanana, R., Randrianirina, F., Gousseff, M., Dubois, N., Razafindratsimandresy, R., Hariniana, E.R., Garin, B., Randriamanantena, A., Rakotonirina, H.C. and Ramparany, L. (2012) Case-Control Study of the Etiology of Infant Diarrheal Disease in 14 Districts in Madagascar. PLoS ONE, 7, e44533.

https://doi.org/10.1371/journal.pone.0044533

[73] da Silva Quetz, J., Lima, I.F.N., Havt, A., de Carvalho, E.B., Lima, N.L., Soares, A.M., Mota, R.M.S., Guerrant, R.L. and Lima, A.A.M. (2010) Campylobacter jejuni and Campylobacter coli in Children from Communities in Northeastern Brazil: Molecular Detection and Relation to Nutritional Status. Diagnostic Microbiology and Infectious Disease, 67, 220-227.

https://doi.org/10.1016/j.diagmicrobio.2010.02.025 
Appendix 1: Study Questionnaire

KENYA MEDICAL RESEARCH INSTITUTE/ILRI

Questionnaire on prevalence and risk factors associated with Campylobacter infection in diarrheal patients in Busia County, Kenya.

Date of recruitment

Patient id/Barcode

Personal Data:

Date of birth

Place of Residence

Gender $\square$ Male $\square$ Female

Contact Tel/Address

1. Occupation: What is your current occupation/workplace

Business

Unemployed

Poultry farming

Employed

Others

2. Educational level: Which is your highest level of education?

None

Primary

Secondary

Tertiary

3. Clinical signs and symptoms

Onset of diarrhea days. Temperature $\left({ }^{\circ} \mathrm{C}\right)$.

During illness, was there any of the following symptoms? Please tick all relevant answers

Key: DK/NS: don't know/Not sure

Yes No DK/NS

Vomiting

Diarrhoea....

Stomach Cramps...

Fever.

Chills

Headache.

Fatigue...

Consistency of stool Mucoid

$$
\begin{aligned}
& \text { Bloody } . . \\
& \text { Watery }
\end{aligned}
$$

Foul smell

- Were you/was your child) given any antibiotics?

- When did you/your child diarrhea last? hrs. How many times/day...

- Vaccine compliant

\section{Environmental Risk Factors}

Which of the following describes where you live?

- City/Urban

- Rural/Village

- Type of water used: 
Which type of water do you usually use:

Borehole

Tap

River

Pond

Lake

5. Dietary habit: Do you/your child usually eat the following (>3/week)

$$
\text { Yes No DK/NS }
$$

Chicken

Pork

Beef

Raw milk

Eggs or food containing eggs

Fish

Raw fruits/fruit salad/vegetables

Breast milk

- Where do you usually purchase food for home consumption?

Grocery stores

Individual farmyard

Local market

Others, specify

- Do you have cutting board for food?

Yes

No

If yes, how do you clean it before use?

Rinse with water

Wash with detergent/soap then clean with water

Others, specify.....

6. Exposure information in the last 10 days before onset of diarrhea

Do you keep/rare or have contact with the following at home?

Yes No DK/NS

- Domestic pets ( e.g. dog, cat)

- Person (s) suffering from diarrhea in your household?

Are you on any long term medication or have you undergone surgery?

If yes, specify.

- Have you/your child finished the childhood vaccines recommended by Kenya Expanded Immunization Program

\section{Travel}

Did you/your child travel outside the County

If yes (specify) Date Where

- Fecal disposal Yes No

Do you have toilet facility if so

Do you use the toilet regularly? 


\section{Economic factors}

- Type of house:

Permanent

Semi-permanent

Thatched with mud soil

- Type of lighting system in the house:

Electricity

Solar

Paraffin

- What do you use for cooking at home?

Firewood

Charcoal

Paraffin electricity

Gas

This is the end of the formal interview. Thank you very much for your time and cooperation.

Do you have any questions?

Thanks and Good bye. 